\title{
A CRITIQUE OF JACQUES ELLUL (FRENCH PHILOSOPHER) ON TECHNOLOGY
}

\author{
George A Lotter \\ Prof., North-West University, South Africa
}

\begin{abstract}
In this paper it is investigated if the influential book published in 1990 by the French philosopher Jacques Ellul about The Technological Bluff was valid in its predictions about the development of technology. The main thesis of the book was that technology always begets more technology and he warned against the "absolutization of the scientific design". It will be shown how influential this book is today while Ellul's legacy is still kept alive. A critical discussion of Ellul's book will be given and the development of current technology, followed by some pointers in dealing with current technology, conclusion and a summary.
\end{abstract}

\section{KEYWORDS}

Ellul, Technology, French Philosopher

\section{INTRODUCTION}

The problem statement this paper will be focusing on, is whether what the French philosopher Jacques Ellul had written in The Technological Bluff is fictitious or relevant. A short overview on different positions regarding the influence of technology on human beings will be given, followed by a discussion on the views of Ellul and a critique of it to see if they are still applicable in the new millennium. Technology, the internet and cyberspace have developed and give an excellent opportunity to evaluate Ellul views and if it really happened what he had predicted in 1990. Following that, some suggested pointers will be proposed in dealing with "modern technology" (as typified by Ellul), a conclusion and a summary of the paper will be given.

\section{ELLUL'S VIEW ON TECHNOLOGY}

The French philosopher Jacques Ellul (1912-1994) is well-known for reflection and critique on technology and the influence it would have in the world. In searching the WWW one still finds many references to Ellul, in the Google site for instance, about 26500 hits by March 1st 2019.

Ellul had altogether written 43 books in which four where he had specifically critiqued the overestimation of science's potential in technology. They are: The Technological Society; Propaganda: The Formation of Men's Attitudes; Perspective on Our Age and the last one: The Technological Bluff.

There is even an International Jacques Ellul Society (http://www.ellul.org/ijes.htm ) which has it as their aim to preserve and make broadly available and support his legacy. In this paper only The Technological Bluff will be discussed as the magnus opera of Ellul.

The Technological Bluff is a comprehensive work of 412 pages (without the bibliography) divided into 22 chapters. It was first published in French with the title Le bluff technologique and translated by G W Bromiley in 1989 and published in 1990. The difficulty with the translation into English is explained by Bromiley himself:

Established usage in English makes it difficult to retain the distinction that Ellul himself always makes and emphasizes between la technique (technique) and la technologie (technology). It should be remembered, however, that in the title Ellul has the stricter sense in view, is technology as discourse, study, or system. 
For the purposes of this paper, technology will be focused on as an overarching term for all development in that area.

The book makes for difficult reading and is definitely not material for leisure and relaxation!

In all the books Ellul had written, he dealt in more or lesser terms with his view of technology as something which, when "...let out of the laboratory, cannot be turned off", and suggested that technology begets more technology. Ellul also predicted that when technology triggers unforeseen events (Ellul, 1990:82) and warned against the absolutization of the scientific design as well as its having a trait of "imperialism" and described the bluff of "consisting essentially of rearranging everything in terms of technical progress".

A limitation the English reader of the book experiences, is that Ellul often refers to other French authors which are not accessible and can therefore not be consulted independently.

Just by gleaning the chapter names and divisions, one gets the idea that Ellul is very much against many of the developments of technology: he uses words like uncertainty, ambivalence, internal contradictions, unreason, philosophy of the absurd, waste, the bluff of productivity and even terrorism in the velvet glove of technology (which may have a prophetic ring to it if one bears in mind how terrorists use technology today!).

Another observation is that Ellul coined (or used) words which have strong emotional contents to it like technocrats and meritocracy (Ellul, 1990:24), showing that the (then) contemporary rulers, the aristoi, are those who have the greatest technical competence (Ellul, 1990:25). He mentions that the America invented the technopolis (Ellul, 1990:27) and suggests that all powers pass through the hands of a group of technocrats in the technopolis (most probably a city run by and exist due to technology).

A fresh breeze is however detected in chapter V where he deals with humanism (Ellul, 1990:125 ff) and writes: "Human freedom supposedly increases with every new technical advance", and: "The development of technique is for humanity alone" (Ellul, 1990:127). This positive view is (again) qualified by a warning where he makes a connection between the use of technique to suppress people and the possibility which is pursued by for instance the military to use it against human beings (Ellul, 1990:131) being the very opposite to the humanistic discourse!

Ellul saw the power of the media as another example of technology exerting control over human destiny (cf also Ellul, 1990:347 ff) and manipulated by special interests, whether by the market, society or the state. The reference to Ellul then gives the connection:

Jacques Ellul has theorized that technologies available to modern societies, specifically the sciences of public opinion (e.g., polling and surveys) and sociology distinguishes modern propaganda from what he termed "primitive" propaganda.

\section{CRITIQUE ON THE TECHNOLOGICAL BLUFF}

It is difficult for any anyone to predict exactly what will be happening in the future regarding technology and although Ellul was a philosopher with a good grasp on his contemporary world, he still could not foresee what would happen in this fast-changing world. He admitted in the book itself that forecasting is virtually impossible (Ellul, 1990:87).

Many references show that he worked within older paradigms which were still rampant in 1990 like the discussion of the Industrial Revolution (Ellul, 1990:15) and the description of the "world of gadgets" (Ellul, 1990:257) - whereas humanity has now already entered the phase of the Fourth Industrial Revolution (cf Schwab, 2016).

In a discussion of the "human mastery over technique" Ellul takes a dim view of the result the advancement of technology may have for workers (Ellul, 1990:154), something which has developed into a complete different direction. In fact, some new work possibilities arose from this development, as Lotter (2004:3) indicates, ". . . there is a new world opening up for research in different fields of the Humanities regarding these issues and in which ways the information society can be utilized to the fullest extend (italics by author)." 


\section{RECENT RESEARCH ON THE INFLUENCE OF THE TECHNOLOGY ON HUMAN BEINGS}

A magnitude of research and study with regards to the effect of technology on human beings have been produced at the end of the previous millennium and the beginning of the new millennium (cf inter alia Schuurman [1995]; Hearn [1997]; Katsikides [1998]; Lotter [2003]; Coteanu [2004]; Jutte [2005]; Klang \& Murray [2005]; Scharff \& Dusek [2014]). In these studies different positions towards technology are taken. A synoptic view should be maintained in this paper in order to show how the issues discussed by Ellul are still valid and worth researching in a highly technocratized society (Lotter, 2005:1).

Some criticism come from Matlack (2014:50 ff) regarding Ellul, which should also be taken into account but he ends his article:

We ought instead to take Ellul's book, placed in the context of his larger work, as an appeal to walk a middle path between unrestrained technophilia and reactionary technophobia... (Matlack, 2014: 64).

More recently Scharff \& Dusek (2014) published a standard work which also deals with these issues and in two chapters references are made to Ellul (cf pp 205 \& 430).

Different aspects of the influence of technology (including the internet, WWW, and cyberspace) have been researched as well. They also have a living interactive relationship with the mass communication media (Rushkoff, 1996:31) and spend more time with the TV than their parents did (Beaudoin, 1998:5). Some warn that technocracy is perfected in computerocracy (Schuurman, 1995:20)! The danger also arises (connected to the above-mentioned) of technomyopia which is defined as a

"...a strange phenomenon that causes us to overestimate the potential short-term impacts of new technology. And when the world fails to conform to our inflated expectations, we turn around and we underestimate the long-term implications" (Bucy, 2002:24).

The power and effects of the cyber world has been the area of research for Lotter (2006:7) who refers to at least five different areas where technology could have a detrimental effect on people: cyberaddiction, cyberloneliness, cyberphilia, cybersex and cyberphobia. It is without doubt a field of research which is growing daily, since the influence of the internet is growing every day and with speeded-up inventions and innovations in the technological world, it is virtually impossible to say what the next "tool" may be invented or in which way something unethical, criminal or illegal will be done.

\section{POINTERS ON DEALING WITH TECHNOLOGY}

In order to maintain a balanced view on technology and also put the issues addressed by Ellul in proper perspective, it is necessary to finally at the end of this paper suggest certain pointers which could be used as broad guidelines how to approach technology:

- Gratitude and acknowledgement for the wonderful possibilities opened up by technology. It should never be forgotten that technology was invented and still develops continually for the primary reason of "helping human beings".

- Technology should always be a tool and "slave" to human beings, not a "slave driver" or something people may become addicted to.

- A distinction between the "good" and "evil" uses of technology is important. It should be realized that horrific things are being done with the available technology on the other hand technology are saving lives and giving a better quality of life to many.

- Ethics should always be maintained when dealing with technology and issues like human rights and privacy should be considered.

- Ongoing research in different related disciplines like Sociology, Psychology, Practical Theology and Physiology of the effects technology may have on people, should be done.

- Debates on the crucial issues of the technology in society and the role it plays should be allowed and encouraged. 


\section{CONCLUSION}

It is clear to any observer that Ellul had done a tremendous amount of research for this work, hence the interest still abounding nearly 30 years on. He was trying to explain most of the areas where technology will affect people's lives and what influence it may have. He addressed the French context, but also referred to the USA (see inter alia Ellul, 1990:28, 248, 298) which is an important factor since the most development of technology originated there. Ellul showed all the detrimental effects technological development can have and warned against different kinds of dangers emanating from technology (see inter alia Ellul, 1990:111, 203, 207, 228, $288,350)$.

\section{SUMMARY}

In this paper it is argued that the book by Jacques Ellul in 1990 titled The Technological Bluff is still being read and highly influential and the philosophy regarding technology, is still valid. The main tenet of the book (keeping in mind the "datedness" of it) is discussed and critiqued and the paper ends by proposing certain pointers on how one should go about in dealing with technology in people's lives.

\section{REFERENCES}

Beaudoin, T. 1998. Virtual Faith: The Irreverent Spiritual Quest of Generation X. San Francisco: Jossey-Bass Publishers. Coteanu, C. 2004. Cyber consumer law and unfair trading practices. Hants: Ashgate.

Ellul, J. 1990. The Technological Bluff. Grand Rapids, Mi.: Eerdmans.

Google. 2006. Jacques Ellul. [Online]. Available WW: http://www.google.co.za/search?hl=af\&q=ellul+technological+bluff\&btnG=Google+soek\&meta [Accessed May 31 2006]

Hearn, W.R. 1997. Being a Christian in science. Downers Grove, Ill.: InterVarsity Press.

Jutte, R. 2005. A history of the senses. From antiquity to cyberspace. Cambridge: Polity Press.

Katsikides, S.A. 1998. The societal impact of technology. Brookfield, Ve.: Ashgate Publishers.

Klang, M. \& Murray, A. (ed). 2005. Human rights in the digital age. London: Cavendish Publishing.

Lotter, G.A. 2003. Privacy issues in counselling online. In: Proceedings of the 5th WWW Applications Conference, August 2003. Durban. [Online]. Available WWW: http://general.rau.ac.za/infosci/www2003/ [Accessed 31 May 2006].

Lotter, G.A. 2004. Information society: helping humans or dehumanizing them? In: Proceedings of the Second International Conference on New Directions in the Humanities, July 2004. Prato.

Lotter, G.A. 2005. Technologizing and technocratization: where does the human side fit in? In: Proceedings of the 7th WWW Conference, August 2005. Cape Town. [Online]. Available WWW: http://www.uj.ac.za/www2005/documents/Lotter,\%20GA.pdf [Accessed 31 May 2006].

Lotter, G.A. 2006. Dehumanization by cyberfication. In: Proceedings of the IPSI conference, February 2006. Marbella.

Matlack, S. 2014. "Confronting the Technological Society," The New Atlantis, Number 43, Summer/Fall 2014, pp. $45-64$.

Reed, C. 2004. Internet Law. Text and materials. Cambridge: Cambridge University Press.

Rushkoff, D. 1996. Playing the Future: How Kids' Culture Can Teach Us to Thrive in an Age of Chaos. New York: Harper Collins.

Scharff, R.C. \& Dusek, V. 2014. Philosophy of Technology. The Technological condition. An Anthology (Second Edition). Chichester: Wiley Blackwell.

Schuurman, E. 1995. Perspectives on technology and culture. Potchefstroom : PU for CHE.

Schwab, K. 2016. The fourth industrial revolution: what it means, how to respond. World Economic Forum, 14 Jan. http://www.weforum.org/agenda/2016/01/the-fourth-industrial-revolution-what-it-means-and-how-to-respond Date of access: 16 Jan. 2018. 